\title{
Д.Ш. Харанутова
}

Институт монголоведения, буддологии и тибетологии СО РАН, Улан-Удэ

\section{О способах представления \\ словообразовательных гнезд родственных языков \\ в «Толково-словообразовательном словаре монгольских языков (на примере монгольского, бурятского и калмыцкого языков)»}

Аннотащия: Статья посвящена разработке проблемы составления толковословообразовательного словаря генетически родственных языков. Раскрывается понятие лексико-словообразовательного гнезда. Рассматриваются вопросы организации дериватов внутри гнезда данного типа и размещения гнезд сопоставляемых языков с идентичными вершинами в словаре.

This article is devoted to working out of a problem of drawing up of the explanatory-word-formation dictionary of genetically related languages. The concept of a lexicon-word-formation family of words reveals. The questions of the organization of derivatives in a family of words of the given type and placing of families of compared languages with identical tops are considered in the dictionary

Ключевые слова: сопоставительное словообразование, лексикословообразовательное гнездо, производное слово, мотивационные отношения, деривационные отношения.

Comparative word-formation, a lexicon-word-formation family of words, a derivative word, motivational relations, derivational relations.

УДК: 812.

Контактная информация: Улан-Удэ, ул. Сахьяновой, 6. ИМБИТ СО РАН. Тел. (3012) 433517. E-mail: dkharanutova@mail.ru.

При сопоставительном изучении словообразовательных систем родственных языков наиболее перспективной единицей исследования является словообразовательное гнездо, так как для межъязыкового сопоставительного исследования именно гнездовой подход представляется самым оптимальным. Анализ структуры и семантики словообразовательных гнезд родственных языков невозможен без описания словообразовательных и лексических значений их составляющих, поэтому гнездо предстает как система семантической и словообразовательной деривации. И.А. Ширшовым для этого типа гнезд введено понятие лексикословообразовательное гнездо. «В данном случае гнездо предстает как структурносемантическое целое, в котором смысловые отношения между словами представлены на фоне их структурных связей, а семантический и деривационный аспекты сливаются неразрывно» [Ширшов, 1999, с. 14]. В основе проекта Толковословообразовательного словаря монгольских языков лежит сопоставление лексико-словообразовательных гнезд монгольского, бурятского и калмыцкого языков.

Для выявления состава единиц, участвующих в системной организации словообразования сравниваемых языков, в словаре будут сопоставляться лексикословообразовательные гнезда родственных языков с идентичными исходными словами. Известно, что идентичные слова в близкородственных языках создают различные модификации (есть одинаковые, есть различные), на то имеются раз- 
ные причины. Процессы, которые разводят родственные языки, постепенно усиливают и углубляют различия между ними, наблюдаются не только на уровне деривационных связей, но и на лексическом уровне.

Одной из проблем составления словаря данного типа является вопрос о способах размещения дериватов внутри гнезда и размещения гнезд родственных языков в словаре.

В отношении имеющихся лексикографических изданий заметим, что двуязычные словообразовательные словари, как правило, созданы на материале разноструктурных языков. Словообразовательные словари родственных же языков, составленных гнездовым методом, да еще и трехъязычных, отсутствуют. В монголоведении опыт составления словообразовательного словаря гнездового типа представлен «Словообразовательным словарем калмыцкого языка» (составитель Д.А. Сусеева), но не существует словообразовательного словаря бурятского языка и сравнительного словообразовательного словаря монгольского, калмыцкого и бурятского языков. При создании «Словообразовательного словаря калмыцкого языка» использован опыт составления «Школьного словообразовательного словаря русского языка» А.Н. Тихонова [Тихонов, 1990], где также применяется ступенчатый принцип: дериваты, образованные непосредственно от вершины гнезда, находятся на первой ступени, производные от них - на второй ступени и т.д. При таком способе фиксируется словообразовательная структура, четко выражены деривационные связи. Рассмотрим, к примеру, состав производных слов словообразовательного гнезда с вершиной ду/н [Сусеева, 1997, с. 109]:

\begin{tabular}{|c|c|c|c|}
\hline $\begin{array}{l}\text { калм. } \\
\text { ду/н } \\
\text { голос; } \\
\text { песня; } \\
\text { звук }\end{array}$ & 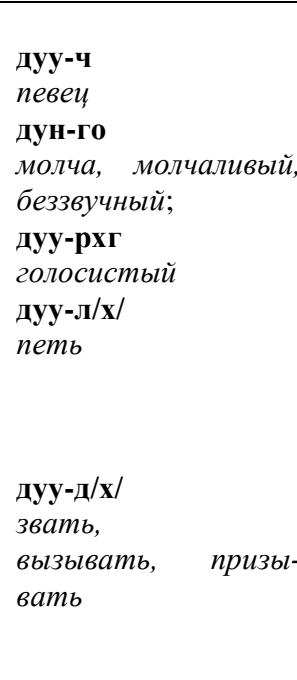 & 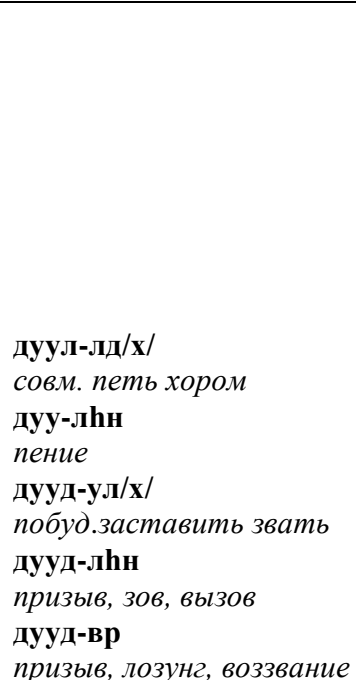 & $\begin{array}{l}\text { дууллд-а/н } \\
\text { пение хором } \\
\\
\text { дуудул-льн } \\
\text { зов } \\
\text { дуудлһн-а } \\
\text { призывной }\end{array}$ \\
\hline
\end{tabular}

Конечно, имеются расхождения в понимании словообразовательного гнезда русского и калмыцкого языков, связанные с разноструктурностью сопоставляемых языков. «Словообразовательные гнезда в монгольских языках наряду с универсальными имеют особенные, связанные с грамматическим строем монгольских языков, и специфические, связанные с национальными чертами каждого конкретного языка» [Сусеева, 1994, с. 26]. В калмыцком словообразовательном словаре дано более широкое понимание производности по сравнению со «Словообразовательным словарем русского языка» А.Н. Тихонова. Если в словообразовательном словаре русского языка гнезда возглавляют только свободные корневые морфемы, то гнезда в калмыцком словаре возглавляют и связанные корни, так как связанность корней - явление частотное для монгольских языков. Также при описании калмыцкого словообразовательного гнезда нередко применяется этимологический критерий. 
В работе «Проблемы аффиксального словообразования калмыцкого и монгольского языков» Д.А. Сусеевой на основе 1900 словообразовательных гнезд калмыцкого языка, 2840 гнезд монгольского языка, в том числе 1177 общих гнезд дается описание структуры монгольского словообразовательного гнезда. Данным автором подготовлен черновой вариант сопоставительного словообразовательного словаря монгольского и калмыцкого языков, где слова внутри гнезда расположены согласно ступенчатому принципу, сравниваемые гнезда расположены параллельно. Каждая статья словаря начинается с монгольского гнезда, а затем параллельно дается калмыцкое гнездо. Например:

\begin{tabular}{|c|c|c|c|c|c|}
\hline $\begin{array}{l}\text { Монг. } \\
\text { Гал } \\
\text { огонь; } \\
\text { пожар; } \\
\text { огненный }\end{array}$ & 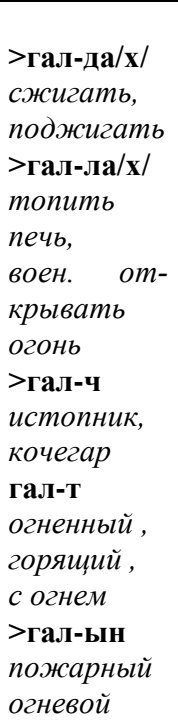 & $\begin{array}{l}\text { >галл- } \\
\text { ур } \\
\text { горелка }\end{array}$ & $\begin{array}{l}\text { Калм. } \\
\text { һал } \\
\text { огонь, } \\
\text { огненныий }\end{array}$ & 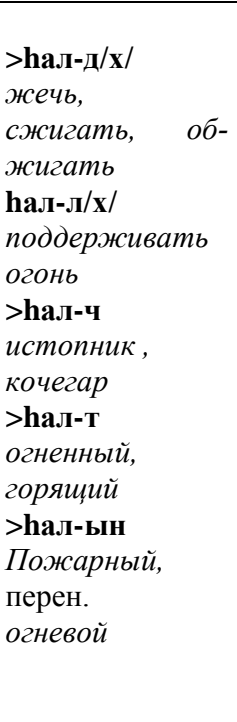 & $\begin{array}{l}\text { >һалд-ул/x/ } \\
\text { быть } \\
\text { сожженнымм, } \\
\text { подвергнуть } \\
\text { огню }\end{array}$ \\
\hline
\end{tabular}

В словообразовательных гнездах, приведенных выше (они извлечены из чернового варианта монгольско-калмыцкого словообразовательного словаря Д.А. Сусеевой), мотивационные отношения между словами не отражены, главным является отражение формальной выводимости одного слова из другого. Данный вид подачи материала подходит для сопоставительного словообразовательного словаря, при условии, что для сравнения будут подобраны малочисленные гнезда. Для сопоставительного трехъязычного толково-словообразовательного словаря такой подход не приемлем, так как ступенчатый характер описания не даст возможности развернуть родственные лексико-словообразовательные гнезда с идентичными вершинами с учетом принципа наглядности. Кроме того, гнезда будут слишком громоздкими в связи с тем, что опираются на лексическое гнездо. Объемное гнездо повлечет за собой пространное описание, много места займет толкование каждого деривата.

В сопоставительном трехъязычном словаре подача материала должна быть несколько иной, нужен другой способ организации слов внутри гнезда. «Толковословообразовательное гнездо - это гнездо комбинированного типа. В нем представлены два основных параметра - семантический и словообразовательный: один характеризует слово с деривационной точки зрения, второй - со стороны значения» [Ширшов, 2004, с. 135]. В «Толково-словообразовательном словаре русского языка» способ описания гнезд - структурно-перспективный (по направлению словообразовательных связей). При использовании данного способа заглавное слово статьи предстает как цельнооформленная единица, продемонстрирован словопроизводственный процесс, обозначена словообразовательная структура слова. Также используемый способ помогает фиксировать явления полимо- 
тивированности и поликоррелятивности, обозначить все мотивационные связи слов. Поэтому целесообразно при описании лексико-словообразовательных гнезд в толково-словообразовательном словаре родственных языков опираться на положения, которые содержатся в концепции И.А. Ширшова [Ширшов, 1999].

Способ подачи слов в гнезде алфавитный, вершина гнезда выделяется, занимает крайнее левое положение. Производные внутри гнезда расположены без фиксации их словообразовательной структуры, потому что вслед за каждым заглавным словом в квадратных скобках подается словообразовательная пара в направлении от производящего к производному. У производящего указываются грамматические морфемы, отсеченные сегменты (они даются в круглых скобках), показаны морфонологические явления на морфемном шве. Направление словопроизводственного процесса обозначается стрелочкой, затем в скобке подается производное слово со словообразовательной структурой. Для слов каждой парадигмы свой отступ от позиции вершины гнезда, к каждому значению производного слова подобран пример. Например:

Бата 1. твердый, крепкий, прочный. Б. бэетэй $x Y н$ 'человек атлетического телосложения, досл. человек крепкого телосложения'; 2. надежный, верный, постоянный. Б. Үәэ `правдивое слово`.

Батадаха [бата > бата-да/ха]. 1. быть слишком крепким (или прочным); 2. упрочиваться, укрепляться, утверждаться (к бата в 1 знач.).

Батадхал [батадаха $>$ батадха-л]. Упрочение, укрепление (к батадаха во 2 знач.).

Батадхаха [батадаха > батадха-ха]. Упрочивать, укреплять (к батадаха во 2 знач.).

Батажаха [бата > бата-жа/ха] 1. Упрочиваться, укрепляться, приобретать силу; 2. утверждаться, обретать устойчивость (или долговечность) (к бата в 1 знач.).

Батажуулха [батажаха > батаж-уул/ха]. побуд. Упрочивать, укреплять (к батажаха в 1 знач.) $)^{1}$.

Батажал [батажаха > батажа-л]. 1. Упрочение, укрепление (к батажаха в 1 знач.); 2. крепость, монолитность (к батажаха во 2 знач.).

Батажанхай [батажаха > батажа-нхай]. Крепкий, ставший на ноги (к батажаха во 2 знач.)

Баталха [бата > бата-лха]. 1. Подтверждать, утверждать; 2. удостоверяться, проверять; 3. ратифицировать; 4. гарантировать, заверять; 5. показывать (всем своим видом); 6. демонстрировать; 7. укреплять, скреплять.

Баталамжа [баталха > батала-мжа]. 1. утверждение (к баталха в 1 знач.); 2. санкция, ратификация (к баталха в 3 знач.); 3. выяснение (к баталха во 2 знач.).

Батаар [бата > бат-аар]. 1. твердо, крепко, прочно (к бата в 1 знач.).; 2. надежно (к бата во 2 знач.).

Бата бҮхэ [бата > бата бҮхэ] парн. Крепкий, твердый, прочный (к бата в 1 знач.).

Бата бэхи [бата > бата бэхи] парн. Крепкий, твердый, прочный (к бата в 1 знач.).

Бата нэгэдэл [бата > бата нэгэдэл]. Единение, единство (к бата в 1 знач.).

\footnotetext{
1 «Эти залоговые основы (имеется ввиду побудительный, страдательный, совместный и взаимный залоги) должны рассматриваться в плане словообразования, так как они никак не могут считаться формами одного и того же глагола» [Санжеев, 1958].
} 
В данном гнезде мотивационные и деривационные связи дополняют друг друга, гнездо предстает как единое структурно-семантическое целое. Что касается подачи сопоставительного материала, то здесь обязательно должен работать принцип наглядности.

В языкознании высказывалась мысль об объединении двух соотносительных по общей вершине словообразовательных гнезд в одно совмещенное (унифицированное), поскольку в гнездах такого типа нагляднее проявляются все совпадения и несоответствия. Для описания совмещенных словообразовательных гнезд вводится ряд новых обозначений, не используемых в обычных гнездах. Межъязыковое соответствие обозначается скобкой <, отсутствие соответствия знаком -. На наш взгляд, в толково-словообразовательном словаре монгольских языков совмещенное гнездо будет слишком громоздким и объемным.

Существует совершенно иной принцип построения деривационных возможностей языка - абстрактная модель словообразовательного гнезда, предложенная П.А. Соболевой [Соболева, 1972]. В рамках словообразовательного гнезда деривационные возможности разных частей речи представлены в виде графов. Так, вертикальное ребро изображает субстантивирующий шаг (образование имен существительных), левонаправленное - глаголообразующий шаг, правонаправленное - адъективирующий шаг (образование прилагательных) и горизонтальное адвербиализирующий шаг (образование наречий).

Данное описание словообразовательного гнезда предполагает выявление не только реализованных в речи, но и потенциальных единиц, а также закономерностей, обусловливающих возможность их реализации. В принципе можно построить абстрактные модели словообразовательных гнезд родственных языков с идентичными вершинами (отглагольные, отсубстантивные, отадъективные и т.д.), затем абстрактные гнезда в виде этих схем наложить, используя методику создания унифицированного гнезда. Сказанное позволяет предположить, что для сопоставительного исследования потенциальных возможностей корневых морфем близкородственных языков он приемлем, но в основе данной методики лежит только словообразовательный аспект. Хотя этот способ находится в русле корневого подхода, постулируемого при гнездовом принципе исследования словообразовательных систем, он не подходит для организации толково-словообразовательного словаря родственных языков. Так как за пределами зоны анализа остается лексическая семантика производного слова, ее мотивированный характер. Так же такая постановка вопроса не решит проблем идиоматичности словообразовательных гнезд, не ответит на вопрос, в чем причина различных модификаций гнезд близкородственных языков, да и морфонологические явления останутся вне поля зрения.

В связи с этим в трехъязычном словаре словообразовательные гнезда следует располагать параллельно (для наглядности), объединять их должны идентичные вершины. В этом случае нагляднее проявятся все совпадения и несоответствия, четко выявится набор производных, характерных для одного языка и отсутствующих в другом. Принцип словообразовательного параллелизма, лежащий в основе построения исследуемых гнезд, позволит последовательно осуществить анализ межъязыковых соответствий не только при сопоставлении производных слов в гнездах, но и при характеристике вершин данных гнезд в сопоставляемых языках. Сопоставление отдельных участков параллельно существующих гнезд помогут реконструировать отдельные звенья деривационных связей.

Приведенные аргументы дают основание утверждать, что принцип размещения производных внутри гнезда должен быть структурно-перспективным (как в словаре И.А. Ширшова), а порядок расположения гнезд с идентичными вершинами - параллельный, такой принцип подачи родственных лексико- 
словообразовательных гнезд с толкованием на русском языке можно назвать перспективно-параллельным. Например ${ }^{1}$ :

\begin{tabular}{|c|c|c|}
\hline $\begin{array}{l}\text { Монгольский } \\
\text { Бат 1. твердый, креп- } \\
\text { кий, прочный; 2. на- } \\
\text { дежный, верный, по- } \\
\text { стоянный. } \\
\text { Баттах [бат> бат- } \\
\text { та/х]. 1.быть слишком } \\
\text { крепким (или проч- } \\
\text { ным); 2. упрочиваться, } \\
\text { укрепляться, утвер- } \\
\text { ждаться (к бат во } 2 \\
\text { знач.). } \\
\text { Батдах [батдах > } \\
\text { батда-х]. Упрочивать, } \\
\text { укреплять (к бат в } 1 \\
\text { знач.). } \\
\text { Батжих [бат > бат- } \\
\text { жи/х] 1.Упрочиваться, } \\
\text { укрепляться, приобре- } \\
\text { тать силу; 2. утвер- } \\
\text { ждаться, } \\
\text { устойчивость обретать } \\
\text { долговечность) (к бати } \\
\text { во } 2 \text { знач.). } \\
\text { Батлах [бат > бат- } \\
\text { лах]. 1.Утверждать; } 2 . \\
\text { укреплять. } \\
\text { Баталгаа [бат > ба- } \\
\text { та-лгаа]. Утверждение } \\
\text { (к бата); } \\
\text { Бата [бат > бат-а]. } 1 . \\
\text { твердо, крепко, проч- } \\
\text { но (к бат во } 2 \text { знач.); } \\
2 . \text { надежно (к бат в } 3 \\
\text { знач.). }\end{array}$ & 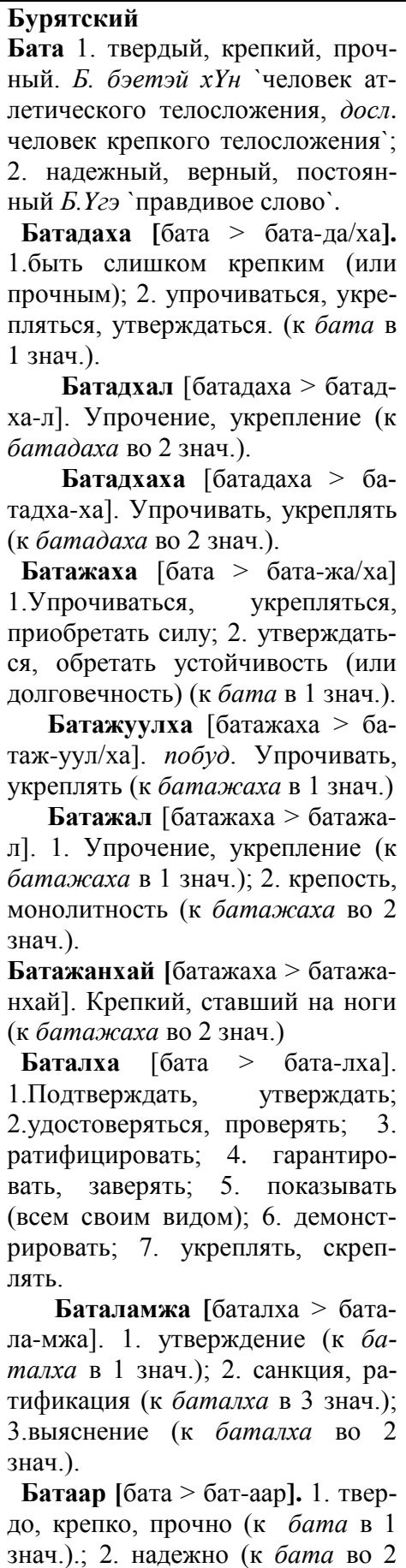 & 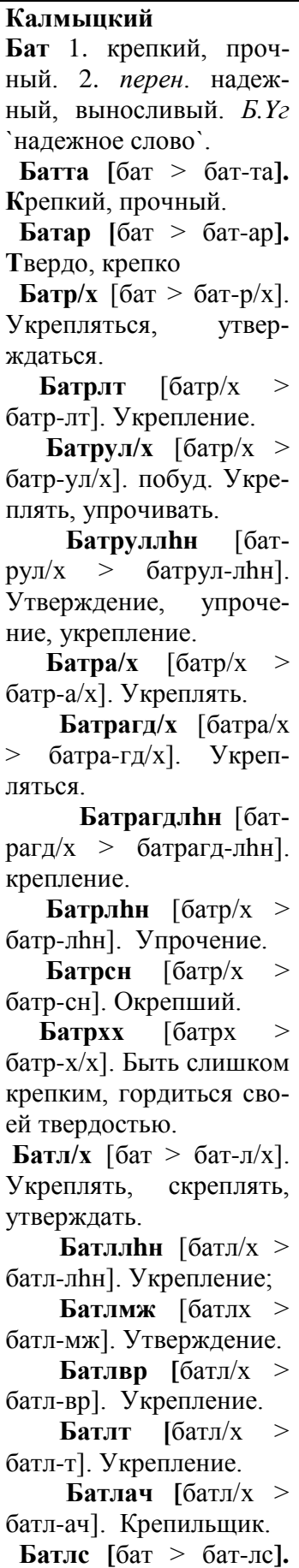 \\
\hline
\end{tabular}

${ }^{1}$ К сожалению, лексико-словообразовательные гнезда монгольского и калмыцкого языков в данном примере составлены на основе словообразовательных гнезд из чернового варианта монгольско-калмыцкого словаря с небольшими дополнениями (в данном случае нас интересует принцип расположения сопоставляемых гнезд данного типа). 


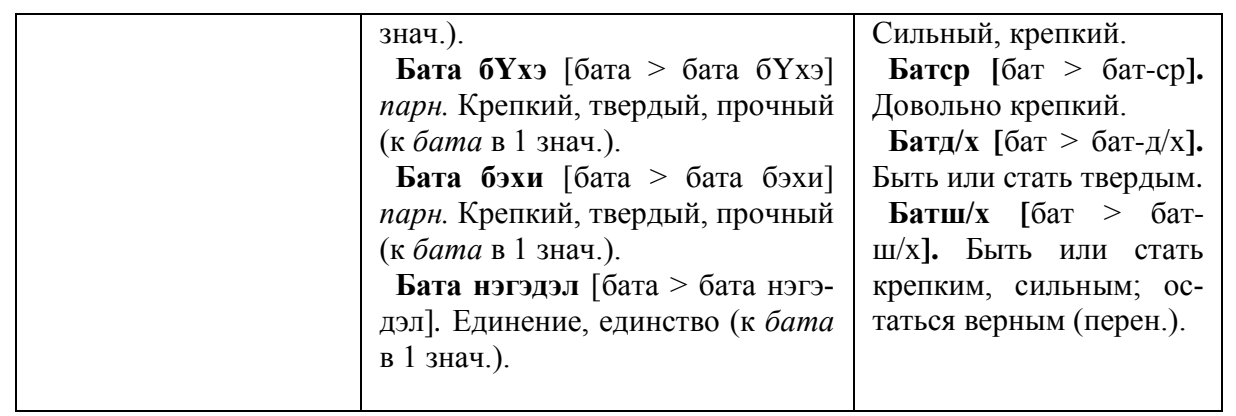

Изложенный способ подачи словообразовательных гнезд в «Толковословообразовательном словаре монгольских языков» считаем наиболее оптимальным. Корректность сопоставительного анализа подтверждается одним и тем же объектом исследования, в роли которого выступают словообразовательные гнезда близкородственных языков с идентичными вершинами (тождественными в плане содержания, близкими в плане выражения). В таком виде гнезда легче типизировать, в них нагляднее обнаруживаются сходства и различия межъязыковых коррелятов, выявляются разные характеры соотношений лексико-семантических вариантов производных и производящих.

\section{Литература}

Манджикова Б.Б. Толковый словарь калмыцкого языка (пособие для учащихся). Элиста, 2002.

Санжеев Г.Д. К вопросу о глагольных основах в монгольских языках // Краткие сообщения Ин-та востоковедения. М., 1958. Вып. 24. С. 3-8.

Соболева П.А. Моделирование словообразования // Проблемы структурной лингвистики, 1971. М., 1972. С. 165-212.

Сусеева Д.А. Словообразовательный словарь монгольского и калмыцкого языков. Рукопись.

Сусеева Д.А. Словообразовательный словарь калмыцкого языка. Элиста, 1997.

Сусеева Д.А. Контрастивная грамматика калмыцкого и монгольского языков. Морфемика. Морфонология. Элиста, 1998.

Тихонов А.Н. Словообразовательный словарь русского языка: В 2 т. M., 1990.

Шагдаров Л.Д., Черемисов К.М. Бурятско-русский словарь: В 2 т. Улан-Удэ, 2008. T. 2. О-Я.

Ширшов И.А. Границы словообразовательного гнезда // Филологические науки. 1996. № 5. С. 43-54.

Ширшов И.А. Теоретические проблемы гнездования. М., 1999.

Ширшов И.А. Способы толкования производных в гнездовом словаре // Ceмантика и прагматика языковых единиц. Калуга, 2004. С. 135-143.

Баярсайхан Хондогынхон Базаррагчаагийн. Монгол хэлний хураангуй тайлбар толь. Улаанбатаар, 2008. 